\title{
Clinical Application of Foldable Capsular Vitreous Bodies in the Treatment of Severe Ocular Trauma and Silicone Oil Dependent Eyes
}

Hao Jiang

Tianjin Eye Hospital

Chao Xue

Tianjin Eye Hospital

Yanlin Gao

Tianjin Eye Hospital

Ying Chen

Tianjin Eye Hospital

Yan Wang ( $\nabla$ wangyan7143@vip.sina.com )

Tianjin Eye Hospital

\section{Research}

Keywords: Ocular trauma, silicone oil dependent eyes, treatment, foldable capsular vitreous body, corneal opacity

Posted Date: August 9th, 2021

DOl: https://doi.org/10.21203/rs.3.rs-751052/v1

License: (9) (1) This work is licensed under a Creative Commons Attribution 4.0 International License. Read Full License 


\section{Abstract}

Background: Recently, a new type of foldable capsular vitreous body (FCVB) has been developed for clinical application to fill the vitreous cavity with vitreous substitutes. It may be an ideal substitute for the vitreous body in eyes with severe retinal detachment. The aim of this study was to assess the application of a foldable capsular vitreous body (FCVB) in the treatment of severe ocular trauma and silicone oil (SO) dependent eyes.

Methods: A retrospective analysis was performed on the clinical application of FCVB in the treatment of severe ocular trauma and SO dependent eyes. The results of best-corrected visual acuity and intraocular pressure (IOP) evaluation, B-scan ultrasonography or color Doppler ultrasonography, ultrasound biomicroscopy, and anterior segment photography were recorded during follow-up. A paired t-test was used to compare the difference in IOP before and after FCVB implantation.

Results: Seven eyes of seven patients were included in the 6 months follow-up. In all cases, B-scan ultrasonography and ultrasound biomicroscopy showed that FCVB adapted closely to the globe wall and ciliary body, thus supporting the retina. Visual acuity did not improve, except in one case from LP to HM. The mean \pm SD IOP was $9.29 \pm 1.60 \mathrm{mmHg}$ prior to FCVB implantation and $10.43 \pm 0.98 \mathrm{mmHg}$ after implantation, with no significant difference between these measurements $(P=0.066)$. Five of the seven patients developed differing degrees of corneal opacity and keratopathy.

Conclusions: FCVB implantation may be a safe and effective method for the treatment of severe ocular trauma and SO dependent eyes. However, corneal opacity and keratopathy are potential serious complications after surgery. Appropriate case selection and proper surgical time require further investigation.

\section{Background}

Since the 1970s[1], pars plana vitrectomy has been used to treat a number of ocular diseases which were previously regarded as immedicable, such as proliferative diabetic retinopathy, proliferative vitreoretinopathy, traumatic proliferative vitreoretinopathy, and endophthalmitis.[2-6] In recent years, the technique of vitrectomy has developed rapidly and indications are increasing.

As the vitreous body is unable to regenerate, it is necessary to fill the vitreous cavity with vitreous substitutes to support the retina after vitrectomy. Several artificial vitreous substitutes, such as inert gas, silicone oil (SO), and heavy SO, have been used clinically.[7-10] However, these vitreous substitutes have several limitations including short residence time, elevation of intraocular pressure (IOP), cataracts, emulsification, keratopathy, and secondary glaucoma.[11-13]

Recently, a new type of foldable capsular vitreous body (FCVB) has been developed for clinical application. It is flexible, effective, and safe as a vitreous substitute and may avoid direct contact with intraocular tissue and reduce complications associated with vitreous substitutes. Therefore, it may be an 
ideal substitute for the vitreous body in eyes with severe retinal detachment.[14-18] Nevertheless, for all new clinical products, further studies are necessary. The purpose of this study was to summarize our experience with the application of FCVB in the treatment of severe ocular trauma or SO dependent eyes.

\section{Methods}

As this was the first cohort of patients undergoing this surgery, we established strict inclusion criteria. All patients had a history of severe ocular trauma, had undergone several operations, had an IOP which could not be maintained with SO tamponade, and satisfied the requirements of FCVB implantation. The exclusion criteria were contraindications approved by the China Food and Drug Administration. The surgical technique has been described previously.[18, 19]

The results of best-corrected visual acuity and IOP evaluation, B-scan ultrasonography or color Doppler ultrasonography, ultrasound biomicroscopy, and anterior segment and fundus photography were recorded in this study. Terms used in the description of ocular injuries conformed to the recommendations of the American Academy of Ophthalmology, the United States Eye Injury Registry, and the International Society of Ocular Trauma.[20]

A paired t-test was used to compare the difference in IOP before and after FCVB implantation.

This study was approved by the Ethics Committee of Tianjin Eye Hospital. Informed consent was obtained from the patients and their families before any examination or treatment was performed.

\section{Results}

Seven eyes of seven patients were included in this study. The characteristics of the seven patients are summarized in Table 1. The participants included six men and one woman, with a mean age of $38.57 \pm$ 11.70 years (range, 17 to 54 years). 
Table 1

Characteristics of 7 eyes

\begin{tabular}{|c|c|c|c|c|c|c|c|c|}
\hline No. & Age & Sex & $\begin{array}{l}\text { Type of } \\
\text { injury }\end{array}$ & $\begin{array}{l}\text { Pre- } \\
\text { ope } \\
\text { VA }\end{array}$ & $\begin{array}{l}\text { Pre-ope } \\
\text { IOP(mmHg) }\end{array}$ & $\begin{array}{l}\text { Surgeries/other } \\
\text { therapies } \\
\text { performed }\end{array}$ & $\begin{array}{l}\text { Final } \\
\text { BCVA }\end{array}$ & $\begin{array}{l}\text { Final } \\
\text { IOP }(\mathrm{mmHg})\end{array}$ \\
\hline 1 & 29 & $M$ & IOFB & NLP & 12 & $\begin{array}{l}1 \text { st : Ocular } \\
\text { repairing 2nd } \\
\text { :vitrectomy + } \\
\text { phaco + SO } \\
\text { injection 3rd : So } \\
\text { removal + FCVB + } \\
\text { SO injection }\end{array}$ & NLP & 10 \\
\hline 2 & 17 & $M$ & rupture & NLP & 9 & $\begin{array}{l}1 \text { st : Ocular } \\
\text { repairing 2nd } \\
\text { :vitrectomy + SO } \\
\text { injection 3rd :SO } \\
\text { removal + FCVB + } \\
\text { SO injection }\end{array}$ & NLP & 11 \\
\hline 3 & 37 & $M$ & penetrating & NLP & 10 & $\begin{array}{l}1 \text { st : Ocular } \\
\text { repairing 2nd } \\
\text { :vitrectomy + SO } \\
\text { injection 3rd :SO } \\
\text { removal + FCVB + } \\
\text { SO injection }\end{array}$ & NLP & 10 \\
\hline 4 & 47 & $F$ & contusion & LP & 8 & $\begin{array}{l}\text { 1st :vitrectomy + } \\
\text { phaco }+ \text { SO } \\
\text { injection }+ \\
\text { cyclopexy 2nd: } \\
\text { SO removal + } \\
\text { FCVB + SO } \\
\text { injection }\end{array}$ & $\mathrm{HM}$ & 9 \\
\hline 5 & 38 & $M$ & rupture & FC & 7 & $\begin{array}{l}\text { 1st: Ocular } \\
\text { repairing 2nd } \\
\text { :vitrectomy + } \\
\text { phaco + SO } \\
\text { injection + } \\
\text { cyclopexy 3rd : } \\
\text { FCVB + SO } \\
\text { injection 4th : so } \\
\text { injection }\end{array}$ & FC & 10 \\
\hline
\end{tabular}

BCVA: best-corrected visual acuity; IOFB: intraocular foreign body; FC: finger counting; NLP: no light perception; LP: light perception; HM: hand motion; SO: silicone oil 


\begin{tabular}{|c|c|c|c|c|c|c|c|c|}
\hline No. & Age & Sex & $\begin{array}{l}\text { Type of } \\
\text { injury }\end{array}$ & $\begin{array}{l}\text { Pre- } \\
\text { ope } \\
\text { VA }\end{array}$ & $\begin{array}{l}\text { Pre-ope } \\
\text { IOP(mmHg) }\end{array}$ & $\begin{array}{l}\text { Surgeries/other } \\
\text { therapies } \\
\text { performed }\end{array}$ & $\begin{array}{l}\text { Final } \\
\text { BCVA }\end{array}$ & $\begin{array}{l}\text { Final } \\
\text { IOP(mmHg) }\end{array}$ \\
\hline 6 & 48 & $M$ & rupture & LP & 10 & $\begin{array}{l}\text { 1st: Ocular } \\
\text { repairing } 2 \text { nd : } \\
\text { anterior } \\
\text { vitrectomy 3rd : } \\
\text { vitrectomy + } \\
\text { phaco + SO } \\
\text { injection + } \\
\text { cyclopexy 4th : SO } \\
\text { removal + FCVB + } \\
\text { SO injection }\end{array}$ & LP & 12 \\
\hline 7 & 54 & $M$ & rupture & $\mathrm{HM}$ & 9 & $\begin{array}{l}\text { 1st: Ocular } \\
\text { repairing } 2 \text { nd } \\
\text { :vitrectomy + } \\
\text { phaco + SO } \\
\text { injection + } \\
\text { cyclopexy 3rd : SO } \\
\text { removal + FCVB + } \\
\text { SO injection }\end{array}$ & $\mathrm{HM}$ & 10 \\
\hline
\end{tabular}

All patients had a history of severe ocular trauma and had undergone several surgeries prior to FCVB implantation (Table 1). Figure 1 shows the severe eye injuries in these cases.

In this study, the last follow-up was at 6 months after FCVB implantation. Among these seven eyes, two eyes underwent four surgeries, four eyes underwent three surgeries, and one eye underwent two surgeries. The time between SO injection and FCVB implantation was $5.29 \pm 3.33$ months (range, 3-13 months). In the first case, the FCVB was refilled with SO due to low IOP because of postoperative oil leakage in the first month after surgery; the IOP remained stable after refilling.

In all cases, B-scan ultrasonography and ultrasound biomicroscopy showed that the FCVB adapted closely to the globe wall and ciliary body and supported the retina well. As shown in Fig. 2A, a layer of mechanical membrane could be seen on the anterior and posterior surfaces, the FCVB position was positive, and the FCVB was well distributed within the vitreous cavity, which adequately supported the retina. Figure $2 B$ shows images six months after FCVB implantation where the FCVB capsule membrane reflex can be seen and the FCVB contacting, but not oppressing the ciliary body is visible.

Visual acuity did not improve, except in one case from LP to HM. Changes in IOP after FCVB implantation are shown in Table 1. The mean \pm SD IOP was $9.29 \pm 1.60 \mathrm{mmHg}$ prior to FCVB implantation and $10.43 \pm$ $0.98 \mathrm{mmHg}$ after implantation. Although IOP was higher postoperatively, there was no significant difference $(P=0.066)$. 
In addition, it is worth noting that five of the seven patients developed severe corneal opacity or keratopathy midway during postoperative follow-up (Fig. 3). In the two cases (cases 2 and 7) with relatively good corneal transparency, the time between $\mathrm{SO}$ injection and FCVB implantation was no more than three months.

\section{Discussion}

Proliferative vitreoretinopathy is a highly probable consequence of severe ocular trauma which usually requires pars plana vitrectomy to prevent disease progression. As the vitreous body is unable to regenerate, it is necessary to fill the vitreous cavity with vitreous substitutes to support the retina after vitrectomy. Therefore, the introduction of an optimal vitreous substitute in the course of a vitrectomy is essential. SO is the most widely used intraocular tamponade in clinical practice; however, it has many drawbacks and limitations, such as elevated IOP, oil emulsification, secondary glaucoma, and keratopathy.[11, 21, 22]

FCVB is a new product that has refined the way in which SO works in the inner cavity of the eyeball.[18] It has been reported that it can prevent the displacement and emulsification of SO,[23] and effectively reduce the post-surgical complications .[16] FCVB filled with SO have been shown to be effective and safe in human eyes[16]; however, we have identified some issues with FCVB in clinical practice. The purpose of this study was to summarize our experience with the application of FCVB.

As FCVB is a relatively new product and was not used at our hospital previously, we were very careful in selecting appropriate patients. All cases in this study had a history of severe ocular trauma and underwent several operations, and IOP could not be maintained with SO tamponade. Initially, we selected only cases with no light perception visual acuity and cases of planned eyeball enucleation. All cases in this study had severe ocular injuries, and the prognoses were very poor.

In this study, with the exception of the shallow anterior chamber, no other structural abnormalities were found after FCVB implantation. B-scan ultrasonography revealed that the FCVB was in good contact with the retina and had good retina-supporting function. Further, no retinal detachment was observed during follow-up. Ultrasound biomicroscopy showed that the FCVB smoothly contacted the ciliary body with no crushing action.

Visual acuity did not improve after FCVB implantation in this study, which is consistent with the results of previous studies.[17, 18, 23]

No significant differences were found in IOP after FCVB implantation, although it was higher postoperatively. In clinical practice, we have observed that postoperative IOP is mainly determined by the function of the ciliary body, rather than by the SO injected into the FCVB. Moreover, we do not suggest excessive injection of SO; the amount of SO injected into the FCVB is usually less than that injected into the vitreous body directly, and an IOP of $15 \mathrm{mmHg}$ may be appropriate. Patients with an iris must have space in the posterior chamber to avoid a shallow anterior chamber. 
We did not encounter severe surgical complications during the follow-up period. Cataract was not found as the lens was lost in the primary injury or lensectomy was performed during the par plana vitrectomy surgery in this study. Other complications such as uveitis, vitreous hemorrhage, endophthalmitis, retinal detachment, and $\mathrm{SO}$ emulsification were not observed during the observation period. Leakage of SO was found in one case, but after refilling with SO, the condition of the eye was stable.

However, serious complications such as corneal opacity and keratopathy were observed in this study. The reason for these may be as follows: first, all eyes in this study had severe injuries and underwent several operations. Thus, the structure of the ocular surface may have changed, leading to an impaired blood supply and nutrition of the cornea. [24] Second, in this study, the time between SO injection and FCVB implantation was $5.29 \pm 3.33$ months, which is relatively long. This may increase the toxic effect of SO on the corneal endothelium and ciliary body.[25, 26] Previous studies[27-29] have reported corneal perforation secondary to SO keratopathy due to poor corneal nutrition. Risk factors include longer duration of oil in the eye, aphakia, SO in the anterior chamber, and extensive and multiple surgeries, all of which were present in our cases. Third, the function of the ciliary body may be impaired by multiple intraocular surgical procedures, inflammation, ciliary body shock, and destruction. Impaired ciliary body function can lead to persistent chronic hypotony and difficulty in the formation of a normal anterior chamber, carrying the risk of corneal opacification.[30] Therefore, it may be inferred that patients with poor ciliary body function may not be suitable for FCVB implantation.

From our cases, it is suggested that SO dependent eyes should not be filled with SO for an extended amount of time before choosing a FCVB implantation to prevent cornea damage. However, if FCVB implantation is performed too early, the postoperative inflammatory response may be severe, and the function of the ciliary body cannot be accurately predicted. In this study, in cases with relatively good corneal transparency, the duration between SO injection and FCVB implantation was no more than 3 months. Therefore, we hypothesized that 3 months may be an appropriate time to implant the FCVB after filling SO for SO dependent eyes. However, this is our experience with a small sample size and requires further research.

There are a few limitations to the present study. The sample size was small and case selection was relatively tight. In addition, a longer follow-up time is required. However, the results remain viable as they provide valuable information for further improvement of surgical outcomes.

\section{Conclusions}

In summary, FCVB implantation may be a safe and effective method for the treatment of severe ocular trauma or SO dependent eyes. Corneal opacity and keratopathy may be common postoperative complications of FCVBs. Appropriate case selection and proper surgical timing may prevent these side effects. Further studies with larger sample sizes and longer follow-up periods are required to evaluate the clinical efficacy of FCVB implantation. 


\section{Abbreviations}

FCVB

foldable capsular vitreous body

SO

silicone oil

IOP

intraocular pressure

BCVA

best-corrected visual acuity

IOFB

intraocular foreign body

FC

finger counting

NLP

no light perception

LP

light perception

$\mathrm{HM}$

hand motion

\section{Declarations}

\section{Ethics approval and consent to participate}

This study was approved by the Ethics Committee of Tianjin Eye Hospital. Informed consent was obtained from the patients and their families before any examination or treatment was performed.

\section{Consent for publication}

Not applicable.

\section{Availability of data and materials}

The data that support the findings of this study are available from the corresponding author Pro Yan Wang upon reasonable request.

\section{Competing interests}

The authors have no proprietary or commercial interest in any of the materials discussed in this article.

\section{Funding}


None.

\section{Authors' contributions}

Hao Jiang, Chao Xue, Yanlin Gao and Ying Chen managed the patient, performed the operation, reviewed the literature and contributed to manuscript drafting; Yan Wang were responsible for the revision of the manuscript for important intellectual content; all authors issued final approval for the version to be submitted.

\section{Acknowledgements}

None

\section{References}

1. Machemer R, Buettner H, Norton EW, Parel JM. Vitrectomy: a pars plana approach. Transactions American Academy of Ophthalmology Otolaryngology American Academy of Ophthalmology Otolaryngology. 1971;75:813-20.

2. Chaudhry NA, Cohen KA, Flynn HW Jr, Murray TG. Combined pars plana vitrectomy and lens management in complex vitreoretinal disease. Semin Ophthalmol. 2003;18:132-41.

3. Castellarin A, Grigorian R, Bhagat N, Del Priore L, Zarbin MA. Vitrectomy with silicone oil infusion in severe diabetic retinopathy. $\mathrm{Br} \mathrm{J}$ Ophthalmol. 2003;87:318-21.

4. Pastor JC. Proliferative vitreoretinopathy: an overview. Survey of ophthalmology. 1998;43:3-18.

5. Yoon YH, Lee SU, Sohn JH, Lee SE. Result of early vitrectomy for endogenous Klebsiella pneumoniae endophthalmitis. Retina (Philadelphia Pa). 2003;23:366-70.

6. Boscia F, Furino C, Prascina F, Delle Noci N, Sborgia L, Sborgia C. Combined surgical ablation and intravitreal triamcinolone acetonide for retinal angiomatous proliferation. Eur $\mathrm{J}$ Ophthalmol. 2005;15:513-6.

7. Azen SP, Scott IU, Flynn HW Jr, Lai MY, Topping TM, Benati L, Trask DK, Rogus LA. Silicone oil in the repair of complex retinal detachments. A prospective observational multicenter study. Ophthalmology. 1998;105:1587-97.

8. Mackiewicz J, Mühling B, Hiebl W, Meinert H, Maaijwee K, Kociok N, Lüke C, Zagorski Z, Kirchhof B, Joussen AM. In vivo retinal tolerance of various heavy silicone oils. Investig Ophthalmol Vis Sci. 2007;48:1873-83.

9. Bhisitkul RB, Gonzalez VH. "Heavy oil" for intraocular tamponade in retinal detachment surgery. $\mathrm{Br} \mathrm{J}$ Ophthalmol. 2005;89:649-50.

10. Baino F. Towards an ideal biomaterial for vitreous replacement: Historical overview and future trends. Acta biomaterialia. 2011;7:921-35.

11. Kleinberg TT, Tzekov RT, Stein L, Ravi N, Kaushal S. Vitreous substitutes: a comprehensive review. Survey of ophthalmology. 2011;56:300-23. 
12. Morescalchi F, Costagliola C, Duse S, Gambicorti E, Parolini B, Arcidiacono B, Romano MR, Semeraro F. Heavy silicone oil and intraocular inflammation. BioMed research international. 2014;2014:574825.

13. Chen H, Feng S, Liu Y, Huang Z, Sun X, Zhou L, Lu X, Gao Q. Functional evaluation of a novel vitreous substitute using polyethylene glycol sols injected into a foldable capsular vitreous body. Journal of Biomedical Materials Research Part A. 2013;101A:2538-47.

14. Lin X, Ge J, Gao Q, Wang Z, Long C, He L, Liu Y, Jiang Z. Evaluation of the Flexibility, Efficacy, and Safety of a Foldable Capsular Vitreous Body in the Treatment of Severe Retinal Detachment. Invest Ophthalmol Vis. 2011;52:374-81.

15. Lin X, Sun X, Wang Z, Jiang Z, Liu Y, Wang P, Gao Q. Three-Year Efficacy and Safety of a Silicone OilFilled Foldable-Capsular-Vitreous-Body in Three Cases of Severe Retinal Detachment. Translational vision science technology. 2016;5:2.

16. Lin X, Wang Z, Jiang Z, Long C, Liu Y, Wang P, Jin C, Yi C, Gao Q. Preliminary efficacy and safety of a silicone oil-filled foldable capsular vitreous body in the treatment of severe retinal detachment. Retina (Philadelphia Pa). 2012;32:729-41.

17. Yan YN, Tian B, Liu Q, Wei WB. [Evaluation of the efficacy and safety of a foldable capsular vitreous body in the treatment of severe retinal detachment]. [Zhonghua yan ke za zhi]. Chinese journal of ophthalmology. 2019;55:259-66.

18. Zhang X, Tian X, Zhang B, Guo L, Li X, Jia Y. Study on the effectiveness and safety of Foldable Capsular Vitreous Body implantation. BMC Ophthalmol. 2019;19:260.

19. Wang P, Gao Q, Jiang Z, Lin J, Liu Y, Chen J, Zhou L, Li H, Yang Q, Wang T. Biocompatibility and retinal support of a foldable capsular vitreous body injected with saline or silicone oil implanted in rabbit eyes. Clin Exp Ophthalmol. 2012;40:e67-75.

20. Kuhn F, Morris R, Witherspoon CD, Heimann K, Jeffers JB, Treister G. A standardized classification of ocular trauma. Ophthalmology. 1996;103:240-3.

21. Ichhpujani P, Jindal A, Jay Katz L. Silicone oil induced glaucoma: a review. Graefe's archive for clinical and experimental ophthalmology = Albrecht. von Graefes Archiv fur klinische experimentelle Ophthalmologie. 2009;247:1585-93.

22. Federman JL, Schubert HD. Complications associated with the use of silicone oil in 150 eyes after retina-vitreous surgery. Ophthalmology. 1988;95:870-6.

23. Lin X, Ge J, Gao Q, Wang Z, Long C, He L, Liu Y, Jiang Z. Evaluation of the flexibility, efficacy, and safety of a foldable capsular vitreous body in the treatment of severe retinal detachment. Investig Ophthalmol Vis Sci. 2011;52:374-81.

24. Kuhn F. Ocular Traumatology. Berlin Heidelberg: Heidelberg Springer; 2008. pp. 467-8.

25. Cinar E, Zengin MO, Kucukerdonmez C. Evaluation of corneal endothelial cell damage after vitreoretinal surgery: comparison of different endotamponades. Eye. 2015;29:670-4.

26. Chen Y, Kearns VR, Zhou L, Sandinha T, Lam WC, Steel DH, Chan YK. Silicone oil in vitreoretinal surgery: indications, complications, new developments and alternative long-term tamponade agents. 
Acta ophthalmologica 2020.

27. Ghosheh FR, Rapuano CJ. Corneal perforation associated with silicone oil in the anterior chamber. Cornea. 2007;26:1129-31.

28. Venkatesh P, Chawla R, Tewari HK. Spontaneous perforation of the cornea following silicone oil keratopathy. Cornea. 2005;24:347-8.

29. Yeung AM, Pherwani A, Tint NL, Ho S, Zaman A, Dua HS. Silicone oil-induced corneal perforation following complex retinal detachment. Retinal cases brief reports. 2009;3:367-8.

30. Utine CA, Gehlbach PL, Zimmer-Galler I, Akpek EK. Permanent keratoprosthesis combined with pars plana vitrectomy and silicone oil injection for visual rehabilitation of chronic hypotony and corneal opacity. Cornea. 2010;29:1401-5.

\section{Figures}




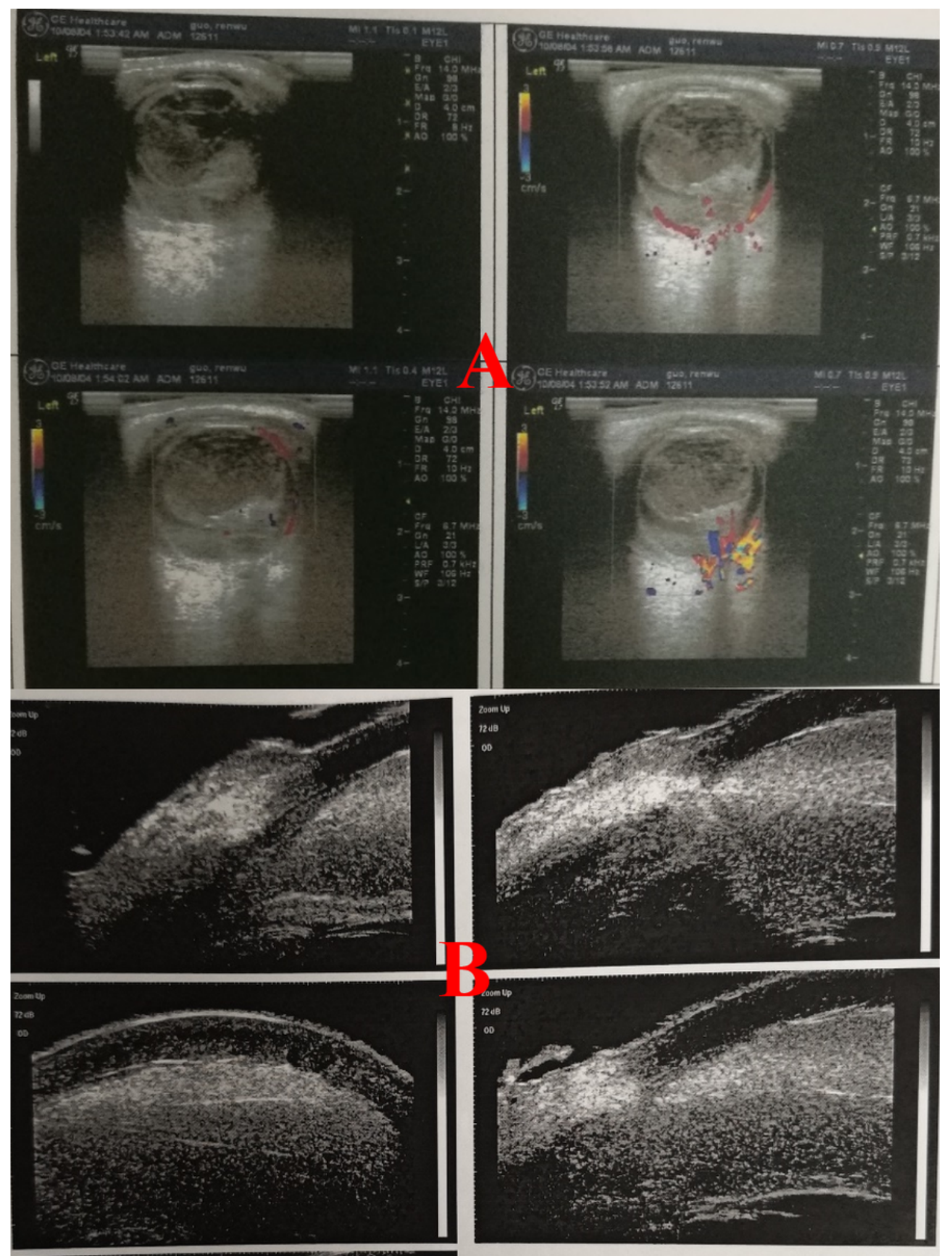

\section{Figure 1}

A: Color doppler ultrasonography of a patient exhibiting vitreous fibroplasias and choroidal and retinal detachment 3 days after repair of the globe. B: Ultrasound biomicroscopy of a patient showing fibroplasias in the anterior chamber. 


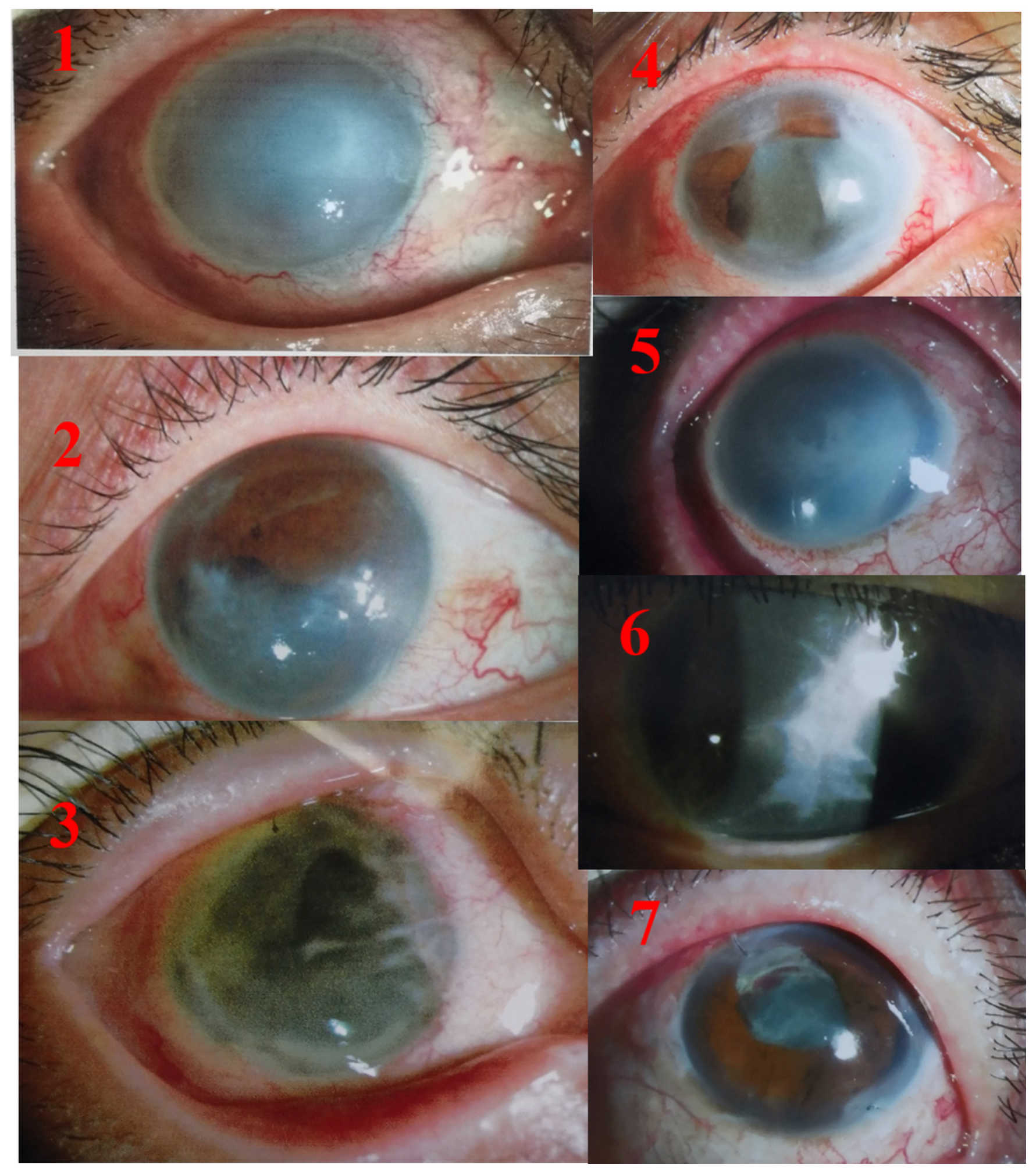

\section{Figure 2}

A: Color doppler ultrasonography of a patient 6 months after FCVB implantation B: Ultrasound biomicroscopy of a patient 6 months after FCVB implantation 


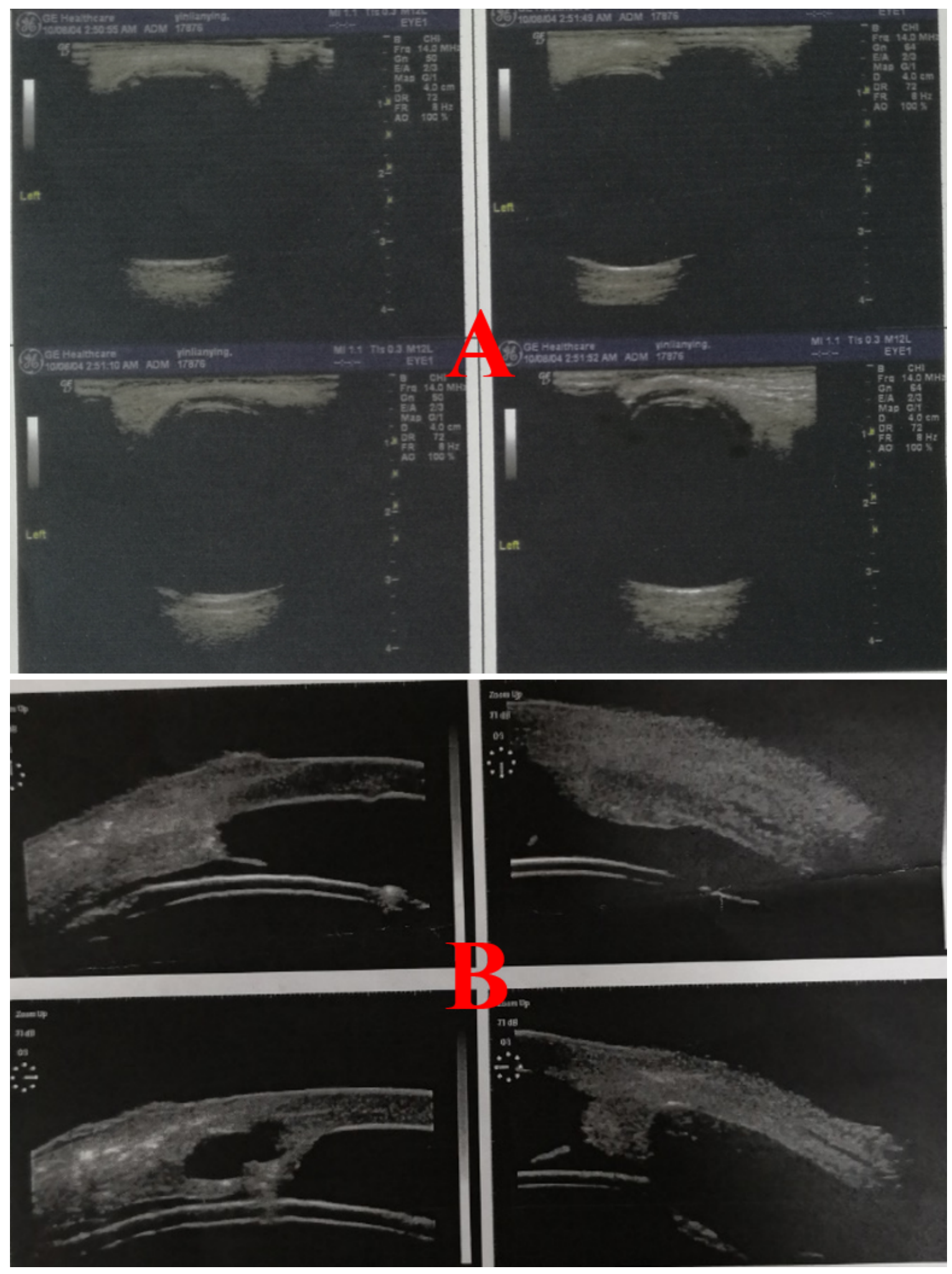

Figure 3

Anterior segment photography of the 7 cases 6 months after FCVB implantation 